\title{
Removal of Copper (II) lons in Aqueous Solutions by Sorption onto Alkali Activated Fly Ash
}

\author{
Lita Darmayanti ${ }^{1,2, *}$, Suprihanto Notodarmodjo ${ }^{1}$, Enri Damanhuri ${ }^{1}$, and Rino R Mukti $^{3}$ \\ ${ }^{1}$ Environmental Engineering Department, Institut Teknologi Bandung, Jalan Ganesha No. 10 Bandung 40132, Indonesia \\ ${ }^{2}$ Civil Engineering Department, Universitas Riau, Kampus Bina Widya Simpang Baru, Pekanbaru Riau 28293, Indonesia \\ ${ }^{3}$ Chemistry Department, Institut Teknologi Bandung, Jalan Ganesha No. 10 Bandung 40132, Indonesia
}

\begin{abstract}
Fly ash is a particulate material produced from coal combustion power plants with major components are silica, alumina, iron oxide, calcium oxide, magnesium oxide, and carbon which are ideal for metal adsorbents. The potential use of fly ash in the wastewater treatment process is obvious because it can be obtained cheaply in large quatities and it can be used as an adsorbent. However, fly ash still shows lower adsorption capacity unless it is activated. In this study, fly ash activated by $\mathrm{NaOH} 14 \mathrm{M}$ and $\mathrm{KOH} 14 \mathrm{M}$ solutions. The batch experiments were carried out to study the sorption of copper ions from aqueous on alkali activated fly ash. The influence of initial concentration and contact time were examined at constant $\mathrm{pH}$ and dose of adsorbent. The sorption capacity of copper ions increased with the initial concentration and contact time. The sorption capacities followed the order Nal $>\mathrm{Ka} 1>\mathrm{FA}$. The adsorption isotherm model exhibited that the Langmuir model is very suitable with copper ions adsorption onto fly ash and alkali activated fly ash. Kinetic study shows that adsorption of copper ions onto FA, Na1, and Kal follows the pseudo second-order kinetics.
\end{abstract}

\section{Introduction}

Rapid industrilization and economic development cause heavy metals to be introduced to environment continuously through point and non-point sourcers. Heavy metals are generated as a rest of metal refinishing products. Therefore, heavy metals pollution is still an environmental problem nowadays in whole of countries. Heavy metals are becoming a public health problem since these elements do not degrade and tend to accumulate in living organism, causing various diseases and disorders. Some of metals like $\mathrm{Hg}, \mathrm{Pb}$, and $\mathrm{Cr}$ can become very toxic to organism, others like $\mathrm{Fe}, \mathrm{Mn}, \mathrm{Cu}$, $\mathrm{Zn}, \mathrm{Ni}$ and Co though essential for living beings, when present in excess certain limits can be very harmful. Copper is highly toxic because it is bioaccumulative, persistent which does not break down in the environment and carcinogenic [1-3].

There are various treatment processes available for treatment metal-contaminated water, such as, chemical precipitation, coagulation, oxidation with ozone/hydrogen peroxide, ion exchange, photo catalytic degradation, and adsorption [4]. Among of these methods, adsorption appears to be the most widely used for the removal of heavy metals [5]. There are many low-cost material have been investigated for removal of heavy metals from water such as hardwood and corn straw [6], oil shale ash [7], carrot residues [8], Lonicera japonica flower biomass [9] and lignin [10,11].
Fly ash is a particulate material produced from coal combustion power plants that requires ultimate disposal. The major components of fly ash are silica, alumina, iron oxide, calcium oxide, magnesium oxide, and carbon which are ideal for metal adsorbents. The potential use of fly ash in the wastewater treatment process is obvious because it can be obtained cheaply in large quatities and it can be used as an adsorbent and as a neutralization agent [12]. Several research reported that significant amounts of heavy metals were removed from solution by adsorption onto fly ash. Sharma [13] studied the removal of chromium from aqueous solutions and wastewaters, Polowczyk [14] examined the efficiency of fly ash agglomerates (particles size 1.0-1.6 mm) for removal of boron from aqueous solution.

However, fly ash still shows lower adsorption capacity unless it is modified. Alkali activation is a technology that can enlarge utilization of fly ash. The alkali activation or geopolymerization formed of mixing the fly ash with alkaline activators and then curing the paste at a certain temperature to result a solid material [15]. Alkali activated fly ash have been more widely used for cement replacement. Nowadays, alkali activated fly ash also used as adsorbent for removal heavy metals with higher adsorption capacity [1,17-18]. The objective of this study is to investigate the effectiveness of alkali activated fly ash for removal copper ion from aqueous solution using batch experiment to determine adsorption kinetic and isotherm.

\footnotetext{
* Corresponding author: litadarmayanti@eng.unri.ac.id
} 


\section{Experimental}

\subsection{Materials}

A sample of the raw fly ash was collected from a coalfiring power plant of PT Trisula Textile, in Bandung city, Indonesia. This material sieved to a particle sizes less than $0,074 \mathrm{~mm}$ (sieve no. 200). All chemical were analytical grade reagents supplied by Merck. Solutions containing copper ions were prepared by dissolving the appropriate weight of $\mathrm{CuSO}_{4} .5 \mathrm{H}_{2} \mathrm{O}$ in distilled water.

\subsection{Alkali activation of fly ash}

Treatment method involved mixed the certain amounts of fly ash with two different alkaline activator, $\mathrm{NaOH} 14$ $\mathrm{M}$ and $\mathrm{KOH} 14 \mathrm{M}$. Liquid/solid ratio was 0.6. After adding all the component, the mixture was mixed for 15$20 \mathrm{~min}$ and poured into polypropylene bottles. Bottles were closed to prevent moisture evaporation. The fresh pastes were heat at $85^{\circ} \mathrm{C}$ for $24 \mathrm{~h}$ in an oven. After that, geopolymer were removed from oven and kept at room temperature for 3 days. Activated fly ash bodies were washed with acetone to remove the excess of alkaline activator and then crushed, sieved to obtain particle diameter less than $0.074 \mathrm{~mm}$, and stored in a desiccator prior to use.

\subsection{Sorption experiments}

The sorption of copper ions on raw fly ash and activated fly ash adsorbent were studied by shaking $0.1 \mathrm{~L}$ of varying $\mathrm{Cu}$ concentration from $5-60 \mathrm{mg} / \mathrm{l}$ at temperature of $25^{\circ} \mathrm{C}$ with a constant amount of adsorbent $(0.15 \mathrm{~g})$ in batch reactors. The mixtures were shaking with horizontal shaker at $250 \mathrm{rpm}$ for $60 \mathrm{~min}$. The concentration of the copper ions in the filtered sample was determinate by atomic absorption spectrophotometer. Duplicate batch were applied for all experiment and mean values were used.

\section{Results and Discussion}

\subsection{Characterisation of adsorbents}

The BET surface areas and pore volumes of fly ash and activated fly ash were obtained from $\mathrm{N}_{2}$ adsorption and given in Table 1 . The fly ash has the lowest surface area and pore volume. Activated fly ash with alkaline activator produces materials with higher surface area and pore volume.

Table 1 Textural properties of fly ash and activated fly ash

\begin{tabular}{lcc}
\hline \multicolumn{1}{c}{ Sample } & $\mathrm{S}_{\mathrm{BET}}\left(\mathrm{m}^{2} / \mathrm{g}\right)$ & $\mathrm{V}\left(\mathrm{cm}^{3} / \mathrm{g}\right)$ \\
\hline Fly ash & 9.5 & 0.022 \\
FA-NaOH & 21.9 & 0.052 \\
FA-KOH & 23.0 & 0.055 \\
\hline
\end{tabular}

Fly ash is an essentially vitreous material (halo recorded at $2 \square=15-35^{\circ}$ ) that also contains a series of minority crystalline phase like Q, M, and H. Activation of fly ash with different solutions change the diffraction pattern. It has to be highlighted the shift in the position of the halo attributed to the vitreous Phase in the initial ash to sligthly higher angular values $\left(2 \theta=20-40^{\circ}\right)$. The changes indicate the formation of an alkaline aluminosilicate gel (Fig. 1).

The original fly ash peaks of quartz, mullite, and hematite were also found in the samples of activated fly ash. However, these peaks tended to lose their intensity. This finding suggest that reactions disorganized the structure of the crystalline of the fly ash particles $(\mathrm{Q}, \mathrm{M}$, $\mathrm{H})$ produced by the alkaline activator. There was also an increase in the number of crystalline compounds which demonstrated on the formation of new crystalline compounds (albite and nahcolite).

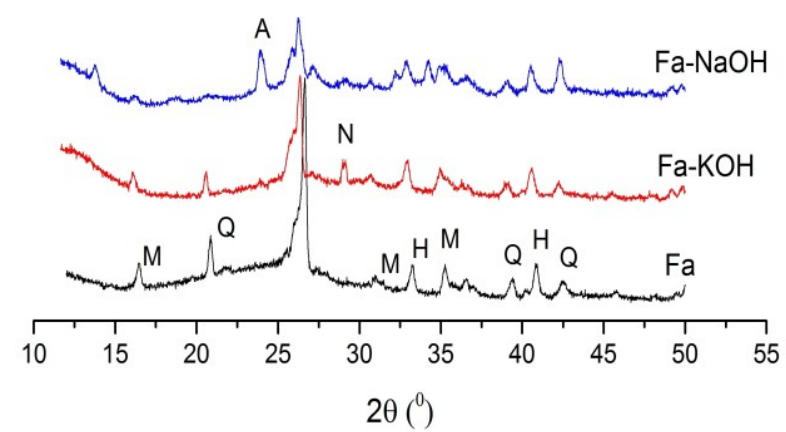

Fig. 1 XRD patterns of fly ash and alkali activated fly ash

The change in morphology of the original surface of the FA particles, can be explained by the dissolution of the vitreous aluminosilicate phase in the raw FA and the crystallization of zeolitic materials onto the external surface of FA particles as pseudomorphs, taking into account that the zeolitic aggregates keep the original shape of the FA spheres after alkaline activation (Fig. 2).

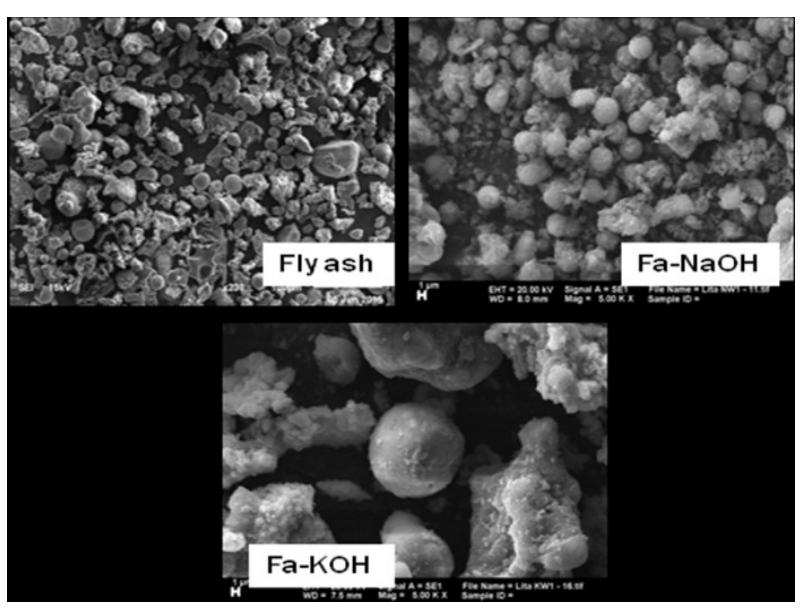

Fig. 2 SEM images of fly ash and synthesis products

\subsection{Factors affecting $\mathrm{Cu}^{2+}$ adsorption}

The removal of $\mathrm{Cu}$ onto fly ash activated by $\mathrm{NaOH}$ (Na1), $\mathrm{KOH}(\mathrm{Ka} 1)$, and raw fly ash (FA) as a function of the their concentrations was studied under the following conditions: $\mathrm{pH}$ : 4; adsorbent dose: $1,5 \mathrm{~g} / \mathrm{l}$, temperature: $25^{\circ} \mathrm{C}$, equilibrium time: $60 \mathrm{~min}$, and initial 
concentrations ranging from 5-60 mg/l. Percentage of $\mathrm{Cu}^{2+}$ removal were compared (Fig. 3).

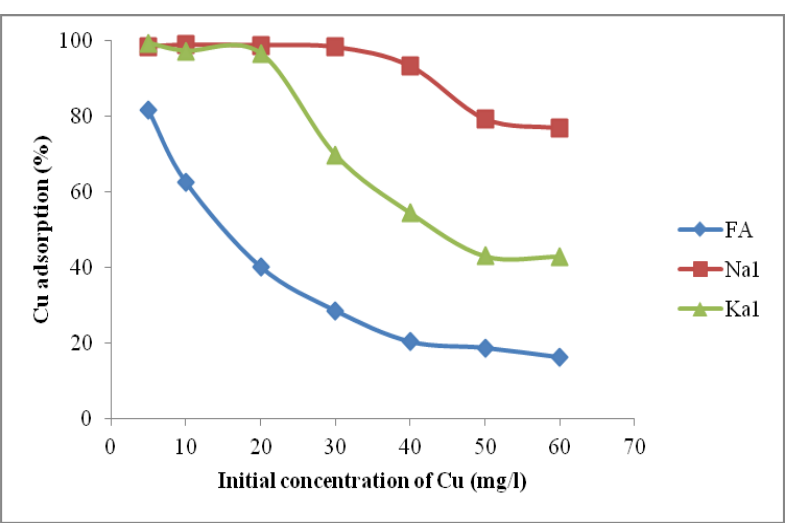

Fig. 3 Effect of initial concentration on $\mathrm{Cu}$ removal efficiency

Percentage of adsorption decrases with increasing initial concentration in aqueous solutions. The removal of $\mathrm{Cu}$ decreases from 81 to $16 \%$, from 99 to $77 \%$, and from 99 to $43 \%$ by adsorption onto FA, Na1, and Ka1 respectively by increasing concentration from 5 to 60 $\mathrm{mg} / \mathrm{l}$. Percentage removal of $\mathrm{Cu}$ was increased when fly ash activated by $\mathrm{NaOH}$ and $\mathrm{KOH}$. This results indicate that adsorption percentage of $\mathrm{Na} 1$ is higher than Ka1.

The $\mathrm{Cu}$ uptake may be attributed to different mechanisms of ion exchange process as well as to adsorption process. During the ion exchange process, metal ions move through the pores of the alkali activated fly ash mass and channels of the lattice and then they replace exchangeable cations ( $\mathrm{Na}$ and $\mathrm{K}$ ). Diffusion was faster through the pores and was retarded when it moved through the smaller diameter channels. In this study, the $\mathrm{Cu}$ uptake could mainly be attributed to ion exchange in microporous of alkali activated fly ash.

The effect of contact time on $\mathrm{Cu}^{2+}$ ions removal was conducted at initial concentration $50 \mathrm{mg} / \mathrm{l}$, adsorbent dose $1,5 \mathrm{~g} / 1$, value of $\mathrm{pH} 4$, temperature $25^{\circ} \mathrm{C}$, and contact time varying from 5 to $120 \mathrm{~min}$. the results are shown in Fig. 4.

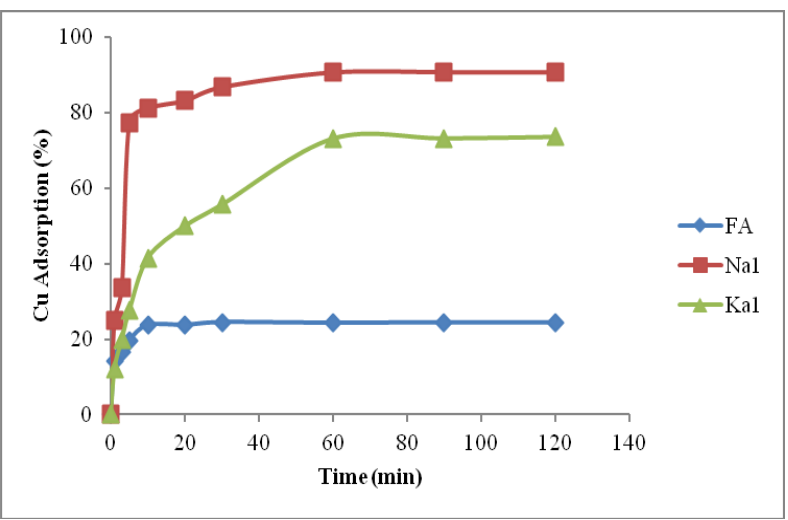

Fig. 4 Effect of contact time on $\mathrm{Cu}$ removal efficiency

The sorption of $\mathrm{Cu}^{2+}$ ions onto alkali activated flyash is depended on time. A significant removal of $\mathrm{Cu}^{2+}$ occurs after 10 min contact time $(23 \%, 81 \%$, and $42 \%$ for $\mathrm{Fa}, \mathrm{Na} 1$, and $\mathrm{Ka} 1$ respectively) and only change slightly in removal efficiency occurred after this period of time. The results ensured that the removal of $\mathrm{Cu}^{2+}$ from the aqueous solution had occurred under equilibrium conditions. As expected, the using of alkali activated pretreatment will increase adsorption performance of $\mathrm{Cu}^{2+}$ onto fly ash. Adsorption of $\mathrm{Cu}^{2+}$ by sorbent that developed in this study is relatively fast and 60 min contact time is suffient to reach the adsorption equilibrium and this contact time was applied in following test.

\subsection{Adsorption isotherm}

Adsorption isotherms are essential to explore the nature interaction between metal ion with adsorbent. The adsorption data have been analysed with two adsorption isotherm methods which are Langmuir and Freundlich equations [19].

\subsubsection{Langmuir isotherm}

The Langmuir adsorption model is based on the asumption that sorption occurs at specific homogeneous sorption sites within the sorbent and intermolecular forces decrease rapidly with the distance from the sorption surface. The model is also based on the asumption that all the sorption sites are energetically idential and sorption occurs on a structurally homogeneous sorbent [19-21]. The equilibrium data for each initial concentration of $\mathrm{Cu}^{2+}$ range from 5 to 60 $\mathrm{mg} / \mathrm{l}$ have been fitted with the Langmuir model (Eq. 1):

$$
\frac{C_{e}}{q_{e}}=\frac{1}{q_{m} K_{L}}+\frac{C_{e}}{q_{m}}
$$

where $\mathrm{Ce}$ is equilibrium concentration of $\mathrm{Cu}(\mathrm{II})$ in solution (mg/l); $\mathrm{q}_{\mathrm{e}}$ is the amount of $\mathrm{Cu}$ (II) adsorbed onto adsobents at equilibrium $(\mathrm{mg} / \mathrm{g}) ; \mathrm{K}_{\mathrm{L}}$ is the Langmuir equilibrium constant related to sorption energy; and $\mathrm{q}_{\mathrm{m}}$ is the maximum sorption capacity $(\mathrm{mg} / \mathrm{g})$.

A linear plot is gained when $\mathrm{Ce} / \mathrm{qe}$ is plotted againts $\mathrm{Ce}$ for the entire of concentration range of $\mathrm{Cu}^{2+}$ studied (Fig. 5). The value of $\mathrm{q}_{\mathrm{m}}$ and $\mathrm{K}_{\mathrm{L}}$ were calculated from the slopes and the intercepts of lines. The isotherm model will effectively and significantly described the sorption data if $\mathrm{R}^{2}$ values $\geq 0.95$.

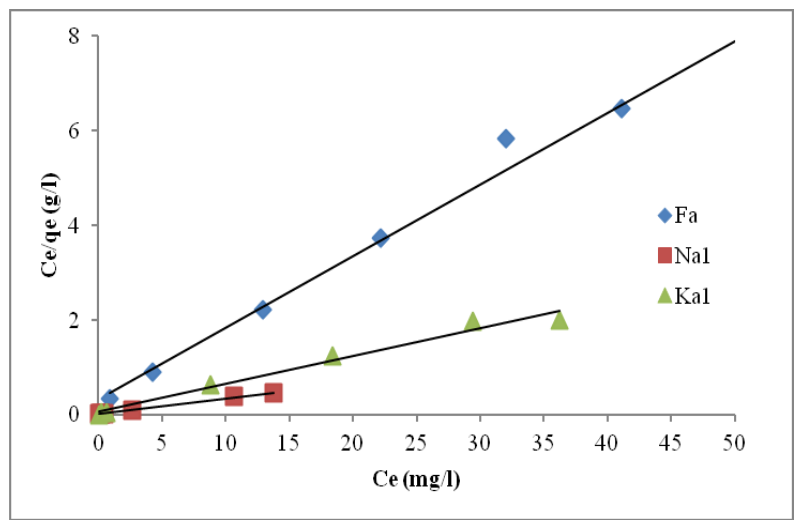

Fig. 5 Langmuir plots for $\mathrm{Cu}^{2+}$ ions adsorption onto fly ash and activated fly ash 
The adsorption data of $\mathrm{Cu}^{2+}$ was found to fit well with the Langmuir isotherm (Table 2). It shows the maximum sorption capacity $\left(\mathrm{q}_{\mathrm{m}}\right)$ which reflects monolayer coverage of sorbent with sorbate and $\mathrm{K}_{\mathrm{L}}$ reflects enthalpy of sorption.

Table 2 Langmuir parameters for $\mathrm{Cu}^{2+}$ adsorption onto fly ashand alkali activated fly ash

\begin{tabular}{cccc}
\hline & \multicolumn{2}{c}{ Langmuir parameters } & \multirow{2}{*}{$\mathrm{R}^{2}$} \\
\cline { 2 - 3 } & $\mathrm{Q}_{\mathrm{m}}(\mathrm{mg} / \mathrm{g})$ & $\mathrm{K}_{\mathrm{L}}(1 / \mathrm{mg})$ & \\
\hline $\mathrm{FA}$ & 6.61 & 0.45 & 0.988 \\
$\mathrm{Na} 1$ & 30.21 & 2.30 & 0.996 \\
$\mathrm{Ka} 1$ & 16.89 & 0.99 & 0.979 \\
\hline
\end{tabular}

Raw fly ash usually has low adsorption capacity. Fly ash can be effective adsorbent depending on the composition and treatment if comparison with other adsorbent. Activation by alkali treatment would increasing the adsorption capacity thus increasing the value for application. Activation by $\mathrm{NaOH}$ more effective from by $\mathrm{KOH}$. Regression coefficient $\left(\mathrm{R}^{2}\right)$ of the plotted isotherm curve show that the Langmuir isotherm found to be suitable for all of the fly ashes. Therefore, $\mathrm{Cu}^{2+}$ ion adsorption of all of the adsorbent that used in this study was estimated as adsorption on a monolayer and sorption occurs on a structurally homogeneous sorbent.

Langmuir isotherm may be reflected by a dimensionless parameter called separation factor. The dimensionless separation factor $\left(\mathrm{R}_{\mathrm{L}}\right)$ was calculated from the Langmuir isotherm using the equation:

$$
R_{L}=\frac{1}{1+K_{L} C_{0}}
$$

Where $\mathrm{K}_{\mathrm{L}}$ is the Lagmuir adsorption constant and $\mathrm{C}_{0}$ is the initial concentration. The $\mathrm{R}_{\mathrm{L}}$ values that were in the range of $0<\mathrm{R}_{\mathrm{L}}<1$ for fly ash and activated fly ash (Table 3). Separation factor indicate that isotherm will be according to the following adsorption characteristics: $\mathrm{R}_{\mathrm{L}}>1$ unfavorable; $\mathrm{R}_{\mathrm{L}}=1$ corresponds to linear; $0<$ $\mathrm{R}_{\mathrm{L}}<1$ is favorable and $\mathrm{R}_{\mathrm{L}}=0$ is irreversible. The results show that the separation factor less than 1 suggests a favorable adsorption [21].

Table $3 R_{L}$ values calculated at different initial concentrations $(\mathrm{mg} / \mathrm{l})$

\begin{tabular}{|c|c|c|c|c|c|c|c|}
\hline \multirow{2}{*}{ Adsorbent } & \multicolumn{7}{|c|}{$\mathrm{R}_{\mathrm{L}}$ at initial concentration } \\
\cline { 2 - 8 } & 5 & 10 & 20 & 30 & 40 & 50 & 60 \\
\hline FA & 0.30 & 0.16 & 0.09 & 0.07 & 0.05 & 0.04 & 0.03 \\
Na1 & 0.07 & 0.04 & 0.02 & 0.02 & 0.01 & 0.01 & 0.01 \\
Ka1 & 0.15 & 0.09 & 0.05 & 0.03 & 0.02 & 0.02 & 0.02 \\
\hline
\end{tabular}

\subsubsection{Freundlich isotherm}

This isotherm developed by Freundlich (1926), describes the equilibrium on heterogeneous surface and does not assume monolayer capacity [7, 22]. The isotherm provides an expression involving the surface heterogenity, exponential distribution of active sites, and their energies. The Freundlich isotherm can be represented as:

$$
\log q_{e}=\log K_{F}+\frac{1}{n} \log C_{e}
$$

Where $\mathrm{q}_{\mathrm{e}}$ is the amount of $\mathrm{Cu}(\mathrm{II})$ ions adsorbed at equilibrium per unit weight of adsorbent $(\mathrm{mg} / \mathrm{g}) ; \mathrm{C}_{\mathrm{e}}$ is the equilibrium concentration of $\mathrm{Cu}^{2+}$ ions in solution $(\mathrm{mg} / \mathrm{l})$; and $\mathrm{K}_{\mathrm{F}}$ and $\mathrm{n}$ are Freundlich constants corresponding to adsorption capacity and intensity respectively. A linear plot is gained when $\log \mathrm{q}_{\mathrm{e}}$ is plotted againts $\log C_{e}$ and the vaues of $K_{F}$ and $n$ can be calculated from intercept and slope of the straight line respectively (Fig. 6). The isotherm parameters are summarized at Table 4.

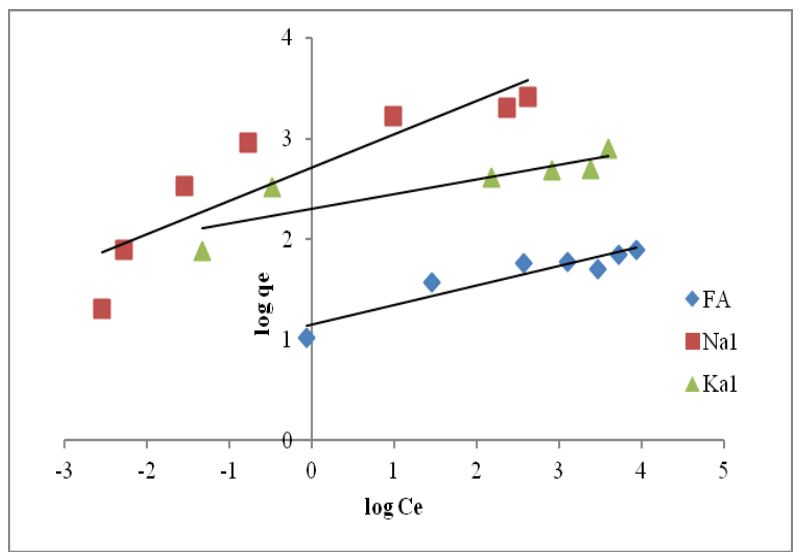

Fig. 6 Freundlich plots for $\mathrm{Cu}^{2+}$ ions adsorption onto fly ash and activated fly ash

Table 4 Freundlich parameters for $\mathrm{Cu}^{2+}$ adsorption onto fly ashand alkali activated fly ash

\begin{tabular}{cccc}
\hline & \multicolumn{2}{c}{ Freundlich parameters } & \multirow{2}{*}{$\mathrm{R}^{2}$} \\
\cline { 2 - 3 } & $\mathrm{K}_{\mathrm{F}}(\mathrm{mg} / \mathrm{g})$ & $\mathrm{n}$ & \\
\hline $\mathrm{FA}$ & 3.16 & 5.16 & 0.886 \\
$\mathrm{Na} 1$ & 15.18 & 3,02 & 0.798 \\
$\mathrm{Ka} 1$ & 8.91 & 5.18 & 0.874 \\
\hline
\end{tabular}

It was found that the Freundlich isotherm fits well with $\mathrm{Cu}^{2+}$ adsorption by raw fly ash. Furthermore, the adsorption intensity $n$ is $>1$ suggesting the existence of a strong bond between adsorbent and adsorbate. Generally, if the exponent lies between $1<\mathrm{n}<10$, it represents advantageous adsorption.

As indicated above, Langmuir model could elucidate the adsorption of $\mathrm{Cu}^{2+}$ on the fly ash and fly ash that activated by $\mathrm{NaOH}$ as well as $\mathrm{KOH}$ since value of $\mathrm{R}^{2}$ Langmuir's are larger than Freundlich's for all of fly ashes. Maximum adsorption capacity of alkali activated by $\mathrm{NaOH}(30.21 \mathrm{mg} / \mathrm{g})$ is higher than activated by $\mathrm{KOH}$ $(16.89 \mathrm{mg} / \mathrm{g})$. This result suggests that the adsorption of $\mathrm{Cu}^{2+}$ onto fly ash and activated fly ash are monolayer. Similar results were also obtained by others [19, 20, 23].

\subsection{Adsorption kinetics}

Kinetic models were used to analyze the experimental data regarding the adsorption mechanism and speed 
control steps. The adsorption process could be controlled with different kind of mechanisms like mass transfer, diffusion control, chemical reaction, and particle diffusion. Several adsorption models were employed to assess the experimental data. The Lagergren's pseudo first-order and pseudo second-order kinetic models were utilized and fitted with the experimental data for evaluate the adsorption process [24]. Fig. 7 and 8 present the plot of the pseudo first-order and pseudo second-order models for adsorption of $\mathrm{Cu}^{2+}$ onto raw fly ash and activated fly ash. Experimental and theoretically calculated adsorption capacities at equilibrium values and coefficients that related to kinetic plots are shown in Table 5.

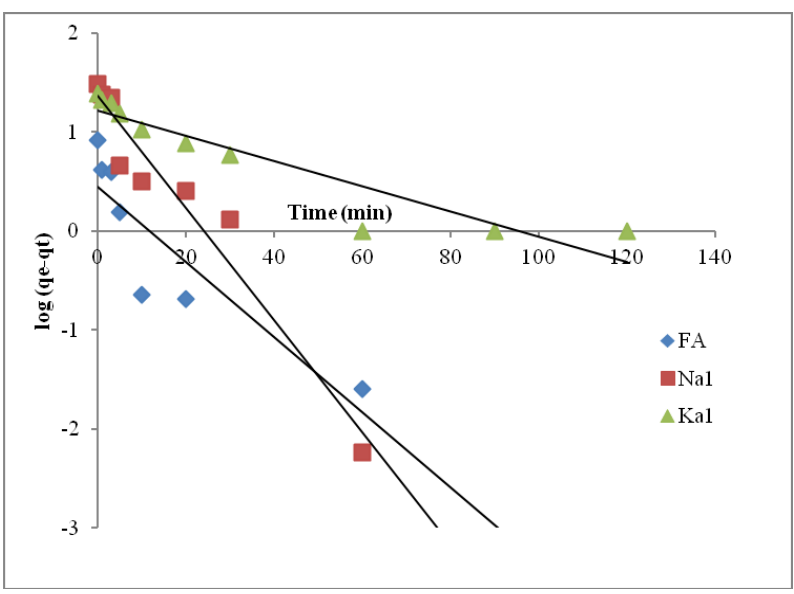

Fig. 7 Fitness of pseudo first-order kinetic

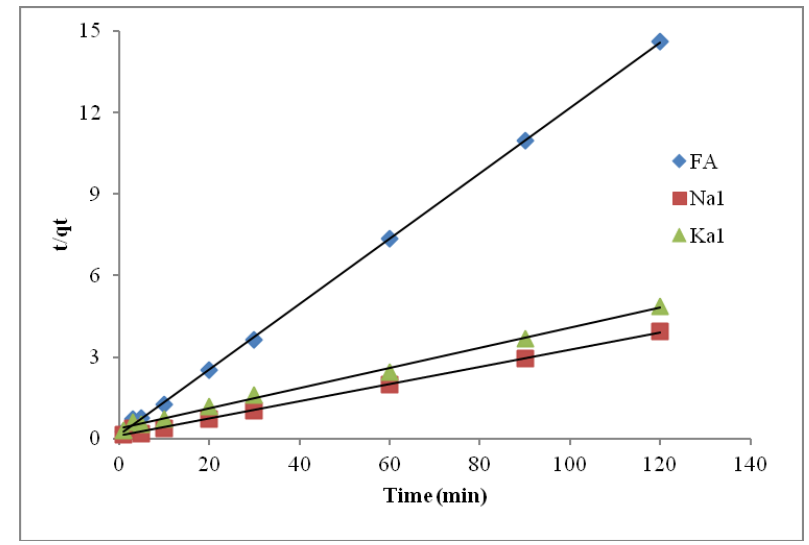

Fig. 8 Fitness of pseudo second-order kinetic

Table 5 Adsorption kinetic model rate constant

\begin{tabular}{|c|c|c|c|c|c|c|c|}
\hline & \multicolumn{3}{|c|}{ Pseudo first-order } & \multicolumn{3}{|c|}{ Pseudo second-order } & \multirow{2}{*}{$\begin{array}{c}\mathrm{q} \exp \\
(\mathrm{mg} / \mathrm{g})\end{array}$} \\
\hline & $\begin{array}{c}\mathrm{qe} \\
(\mathrm{mg} / \\
\mathrm{g})\end{array}$ & $\begin{array}{c}\mathrm{k} 1 \\
\left(\mathrm{~min}^{-1}\right)\end{array}$ & $\mathrm{R}^{2}$ & $\begin{array}{c}\text { qe } \\
(\mathrm{mg} / \mathrm{g})\end{array}$ & $\begin{array}{c}\mathrm{k} 2 \\
(\mathrm{~g} / \mathrm{mg} / \\
\mathrm{min})\end{array}$ & $\mathrm{R}^{2}$ & \\
\hline $\mathrm{Fa}$ & 2.8 & 0,087 & 0,79 & 8.31 & 0.104 & 0.99 & 8.2 \\
\hline $\mathrm{Na} 1$ & 23.5 & 0.131 & 0.94 & 31.45 & 0.009 & 0.99 & 30.4 \\
\hline Ka1 & 21.1 & 0.047 & 0.94 & 27.10 & 0.004 & 0.99 & 24.5 \\
\hline
\end{tabular}

As can be seen from Table 5, the linear correlation coefficient for pseudo first-order is not good when compared to the pseudo second-order model. These results indicate that the adsorption of $\mathrm{Cu}^{2+}$ ions onto fly ash and activated fly ash is not regarding to first-order reaction. It is obvious from the results of the correlation coefficient of pseudo second-order model is very high. Also, the theoretical and experimental qe values are very suitable. This model based on the assumption that the rate limiting step may be a chemical adsorption involving the valence forces through exchange of electrons between the adsorbent and the adsorbate [24, 25].

\section{Conclusion}

Fly ash is a cheap and effective adsorbent for removal $\mathrm{Cu}^{2+}$ ions from aqueous solutions. Changing the nature of fly ash by alkali activated can increase its ability to adsorb $\mathrm{Cu}^{2+}$ ions significantly. The increasing of adsorption capacity of fly ash that activated by $\mathrm{NaOH}$ was greater than fly ash that activated by $\mathrm{KOH}$. The adsorption of $\mathrm{Cu}^{2+}$ ions onto alkali activated fly ash fit the Langmuir isotherm very well as well as the adsorption of $\mathrm{Cu}^{2+}$ ions onto fly ash. Maximum adsorption capacities were calculated from the Langmuir isotherm as $30.21 \mathrm{mg} / \mathrm{g}$ and $16.89 \mathrm{mg} / \mathrm{g}$ for the fly ash that activated by $\mathrm{NaOH}$ and $\mathrm{KOH}$ respectively. The adsorption of $\mathrm{Cu}^{2+}$ ions onto fly ash and alkali activated fly ash follow the pseudo second-order rate kinetics due to being more suitable with experimental data. The adsorption mechanism is a physical process since it contains electrostatic interaction between $\mathrm{Cu}^{2+}$ ions and adsorbent.

\section{References}

1. T.C. Hsu, C.C. Yu, C.M.Yah, Fuel, 87, 1355-1359 (2008)

2. K.S. Hui, C.Y.H. Chao, S.C. Kot, Journal of Hazardous Materials, B127, 89-101 (2005)

3. F.A. Lopez, C. Perz, Journal of Materials Science Letters, 15, 1310-13 (1996)

4. M. Ahmaruzzaman, Colloid and Interface Science, 166, 36-59 (2011)

5. K.G. Bhattcharyya, S.S. Gupta, Advances in Colloid and Interface Science, 140, 114-131 (2008)

6. X. Chen, G. Chen, L. Chen, Y. Chen, J. Lehmann, M.B. McBride, A.G. Hay, Bioresource Technology, 102, 8877-8884 (2011)

7. R. Shawabkeh, Al-Harahsheh, Al-Otoom, Separation and Purification Technology, 40, 251257 (2004)

8. B. Nasernejad, T.E. Zadeh, B.B.Pour, M.E. Bygi, A. Zamani, Process Biochemistry, 40, 1319-1322, (2005)

9. L.P. Lingamdinne, J-K. Yang, Y.Y. Chang, J.R. Koduru, Hydrometallurgy, xx, xxx-xxx (2015)

10. Y. Wu, S. Zhang, Bioresource Technology, 99 (16), 7709-7715 (2008)

11. X. Guo, S. Zhang, X. Shan, Journal of Hazardous Materials, 151 (1), 134-142 (2008) 
12. C.H. Weng, C.P. Huang, Colloids and Surfaces A: Physicochemichal Engineering. Aspects, 247, 137143 (2004)

13. Y.C. Sharma, Uma, S.N. Upadhyay, C.H. Weng, Colloids and Surfaces A: Physicochem. Engineering Aspects, 317, 222-228 (2008)

14. I. Polowczyk, J. Ulatowska, T. Kozlecki, A. Bastrzyk, W. Sawifiski, Desalination, 310, 93-101 (2013)

15. A. Fernández-Jiménez, A. Palomo, Cement and Concrete Research, 35, 1984-1992 (2005)

16. L. Li, S. Wang, Z. Zhu, Journal of Colloid and Interface Science, 300, 52-59 (2006)

17. M. Visa, Applied Surface Science, 263, 753-762 (2012)

18. M. Kobya, Bioresource Technology, 91, 317-321 (2004)

19. A. Papandreou, C.J. Stournaras, D. Panias, Journal of Hazardous Materials, 148, 538-547 (2007)

20. M.S. Al-Harahsheh, K. Al-Zboon, L. AlMakhadmeh, M. Hararah, M. Mahasneh, Journal of Environmental Chemical Engineering, 3, 1669-1677 (2015)

21. S. Mohan, R. Gandhimathi, Journal of Hazardous Materials, 169, 351-359 (2009)

22. S. Wang, L, Li, Z. Zhu, Journal of Hazardous Materials, B139, 254-259 (2007)

23. H. Xiyili, S. Cetintas, D. Bingol, Process Safety and Environmental Protection, 109, 288-300 (2017)

24. Y.S. Ho, G. McKay, Process Biochemistry, 34, 451-465 (1999) 